\title{
Cathodoluminescence study of CdTe crystals doped with Bi and Bi:Yb
}

\author{
P. Hidalgo $\cdot$ J. Piqueras $\cdot$ N. V. Sochinskii $\cdot$ \\ M. Abellán · E. Saucedo $\cdot$ E. Diéguez
}

Received: 3 April 2008/ Accepted: 17 June 2008/Published online: 16 July 2008

(C) Springer Science+Business Media, LLC 2008

\begin{abstract}
Bi doped and Bi and Yb codoped CdTe crystals grown by the Bridgman method have been characterized by cathodoluminescence (CL) in the scanning electron microscope. CL images show a dense network of highly decorated grain boundaries in the Bi doped samples and dopant striations in the codoped crystals, attributed to the presence of $\mathrm{Yb}$. Bi contributes to the appearance of the $\mathrm{A}$ luminescence band at $1.43 \mathrm{eV}$. The influence of $\mathrm{Yb}$ dopant on the CL spectra is discussed.
\end{abstract}

\section{Introduction}

Doping of CdTe crystals with high-Z elements constitutes a very promising way to obtain semi-insulating and photosensitive material suitable for a number of important applications such as room temperature gamma radiation detectors, and infrared optics and optoelectronics [1,2]. In the particular case of CdTe crystals doped with $\mathrm{Bi}$, we have recently demonstrated that these crystals of reasonably good structural quality could be grown from the melt (Bridgman technique), and vapor (Markov technique) and they have high resistivity and

P. Hidalgo $(\bowtie) \cdot$ J. Piqueras

Departamento de Física de Materiales, Facultad de Ciencias

Físicas, Universidad Complutense de Madrid, 28040 Madrid, Spain

e-mail: phidalgo@fis.ucm.es

N. V. Sochinskii · M. Abellán

Instituto de Microelectrónica de Madrid, CNM-CSIC, Polo

Tecnológico de Madrid, Tres Cantos 28760, Madrid, Spain

E. Saucedo · E. Diéguez

Departamento de Física de Materiales, Universidad Autónoma de Madrid, Madrid 28049, Spain photoconductivity at the dopant concentrations close to $10^{17}$ at. $\mathrm{cm}^{-3}[3,4]$. It is also worth mentioning that the $\mathrm{Bi}$ dopant could play an important role in a catalytically driven growth of CdTe nanocrystals and nanowires [5, 6].

Two defect centers associated with $\mathrm{Bi}$ as dopant have been identified in CdTe crystals by photoluminescence and photoconductivity measurements [7]. The first one is associated with a deep level located at $E_{\mathrm{v}}+0.71 \mathrm{eV}$, and it is only present at low $\mathrm{Bi}$ concentrations and it has a complex structure, donor character, and hole-trap properties. It is responsible for the high resistivity and very good photoconductivity of the CdTe:Bi crystals. The second one is an acceptor center located at $E_{\mathrm{v}}+0.30 \mathrm{eV}$, assigned to $\mathrm{BiTe}$ specie, and is mainly present at high Bi concentrations and is responsible for the low resistivity and poor photoconductivity of highly doped CdTe:Bi crystals.

Besides energetic location of the Bi-related defects, their spatial distribution all over the crystal volume as well as their interaction with other structural defects could be essential for the applications of CdTe:Bi crystals. In our previous studies, we have demonstrated that a complementary use of cathodoluminescence (CL) spectroscopy and imaging is a powerful tool to investigate such problems in CdTe doped crystals (for example, see [8] and [9]). In the present paper, we report the results of CL studies of CdTe crystals doped with $\mathrm{Bi}$. Taking into account an increasing interest in the doping of semiconductor compound crystals with rare-earth elements (for example, see [10]), several CdTe crystals codoped with Bi and $\mathrm{Yb}$ were also prepared and investigated.

\section{Experiment}

CdTe:Bi and CdTe:Bi:Yb crystals were grown by the Vertical Bridgman Method in a quartz ampoule with a 
pyrolytic graphite coating, at a growth rate of $0.4 \mathrm{~mm} / \mathrm{h}$ and a gradient temperature in the solidification zone of $5{ }^{\circ} \mathrm{C} / \mathrm{cm}$. The CdTe:Bi crystals were doped with the two Bi concentrations $1 \times 10^{17}$ at.cm ${ }^{-3}$ and $7 \times 10^{17}$ at.cm ${ }^{-3}$ and the respective concentrations of dopants in $\mathrm{CdTe}: \mathrm{Bi}: \mathrm{Yb}$ crystals were $1 \times 10^{17}$ at.cm ${ }^{-3}$ and $1 \times 10^{18}$ at.cm ${ }^{-3}$. More details on the growth setup could be found elsewhere [4].

CL measurements, spectra and images, were carried out in a Leica 440 SEM and a Hitachi 2500 SEM at $78 \mathrm{~K}$. The CL measurements were carried out at liquid nitrogen temperature by using a R5509 Hamamatsu photomultiplier tube at $20 \mathrm{kV}$ of electron beam energy.

\section{Results and discussion}

Figure 1a shows a CL image of the sample doped with $1 \times 10^{17}$ at.cm ${ }^{-3} \mathrm{Bi}$. Grain boundaries appear as dark lines sometimes surrounded by bright bands at both sides. This contrast, which has been often reported in CL studies of semiconductors and insulator materials, is due to the decoration of the boundaries by impurities and/or point defects. The image shows that the interior of the grains is very homogeneous and no precipitates or other non-radiative recombination centers are observed. By increasing the Bi concentration, sample 2, there is a loss of homogeneity with the formation of a higher number of grains or subgrains with boundaries in which the bright bands extend up to about $50 \mu \mathrm{m}$ at both sides of the boundary (Fig. 1b).

The CL spectrum of sample 1 (Fig. 2) shows the near band gap emission band at $1.56 \mathrm{eV}$ and two deep level bands centered at about $1.1 \mathrm{eV}$ and $0.781 \mathrm{eV}$, respectively. Gaussian deconvolution of the most intense band centered at $1.1 \mathrm{eV}$ shows that it has three components at $1.12 \mathrm{eV}$, $1.06 \mathrm{eV}$, and $0.96 \mathrm{eV}$, respectively. The first one can be associated to a level at about $1.1 \mathrm{eV}$ below the conduction band of CdTe, which has been reported in CL and photoinduced current transient spectroscopy studies [11] and it
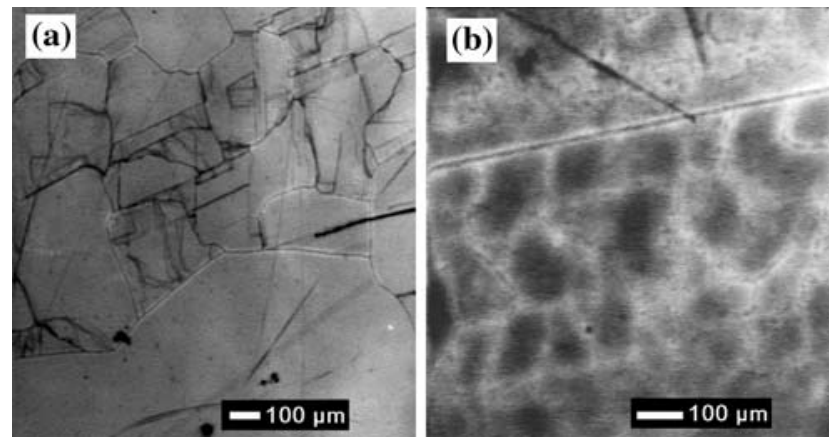

Fig. 1 (a) CL image of the sample doped with $1 \times 10^{17} \mathrm{at.cm}^{-3} \mathrm{Bi}$ (b) CL image of the sample doped with $7 \times 10^{17}$ at.cm $^{-3} \mathrm{Bi}$

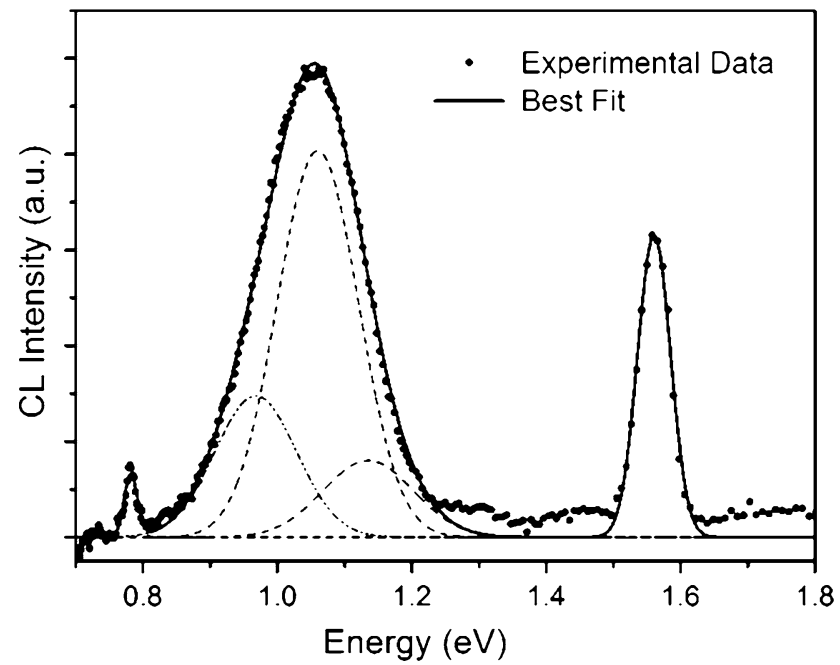

Fig. 2 CL spectrum of sample 1 at $78 \mathrm{~K}$. Gaussian deconvolution of the band centered at $1.1 \mathrm{eV}$ shows this is a complex band. (Full circles) Experimental data, (solid line) Best Fit, and (dash line) Gaussian components

has been previously suggested to be connected with tellurium vacancies $[12,13]$. The other two components are related to cation vacancies and they have an acceptor character [11]. The low energy band at $0.781 \mathrm{eV}$ is also complex, with components at $0.784 \mathrm{eV}$ and $0.775 \mathrm{eV}$, which are related to different states of an acceptor complex involving the native $V_{\mathrm{Cd}}$ defects and impurities.

Figure 3 shows the CL spectrum of sample 2 with bands at about $1.45 \mathrm{eV}$ and $1.34 \mathrm{eV}$, in addition to the near band gap emission at $1.56 \mathrm{eV}$ and the deep level band at $1.1 \mathrm{eV}$, which were also present in sample 1. Comparison of spectra of samples 1 and 2 suggests that the bands at

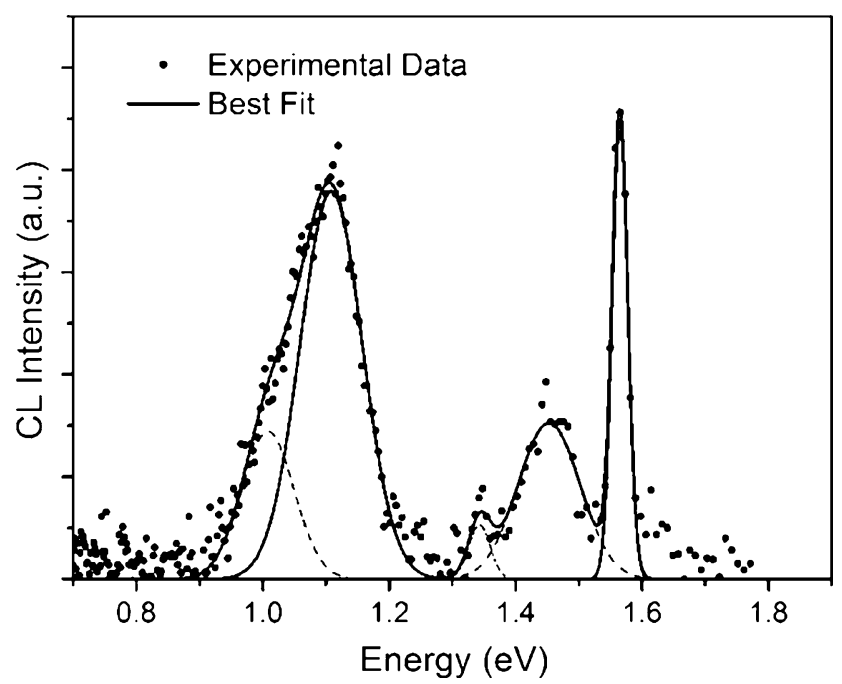

Fig. 3 CL spectrum of sample 2 at $77 \mathrm{~K}$. (Full circles) Experimental data, (solid line) Best Fit and (dash line) Gaussian components 


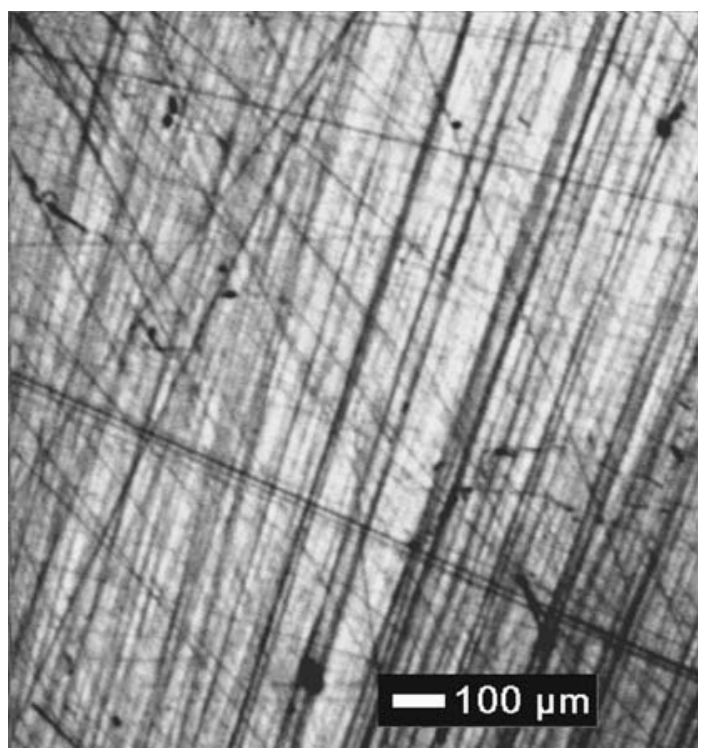

Fig. $4 \mathrm{CL}$ image of the sample codoped with $\mathrm{B}$ and $\mathrm{Yb}$

$1.45 \mathrm{eV}$ and $1.35 \mathrm{eV}$ are related to the dopant. In fact luminescence emissions around $1.4 \mathrm{eV}$ in CdTe have been previously reported in doped and undoped material and have been attributed to $V_{\mathrm{Cd}}$-donor pairs, called $\mathrm{A}$ centers $[14,15]$. In this case the $1.45 \mathrm{eV}$ and $1.35 \mathrm{eV}$ bands would be due to $\mathrm{A}$ centers formed by cadmium vacancies and bismuth atoms.

The main features observed in the CL images of sample 3, codoped with $\mathrm{Bi}$ and $\mathrm{Yb}$, are parallel dark lines as shown in Fig. 4. Such distribution of lines has been reported for other semiconductors $[16,17]$ and is due to dopant concentration variations. In order to determine which dopant gives rise to the striations, EDX maps for $\mathrm{Bi}$ and $\mathrm{Yb}$ were recorded but no spatial variations of these elements were detected. We suggest that the concentration of the element is below the detection limit of the EDX although has a strong influence on the dopant sensitive CL measurements.

The CL spectrum of the codoped sample (Fig. 5) shows the band gap emission, a band at about $1.43 \mathrm{eV}$ (band A) and the low energy band centered at about $1.1 \mathrm{eV}$ also found in the $\mathrm{Bi}$ doped samples. The $\mathrm{A}$ band was not observed in sample 1 , which has the same $\mathrm{Bi}$ content as this sample, which indicates as the presence of $\mathrm{Yb}$ also contributes to this emission. A new radiative center involving $\mathrm{Yb}$ atoms is suggested. The influence of $\mathrm{Yb}$ is also apparent in the $1.1 \mathrm{eV}$ which is broader than in the other samples and show a slight shift to higher energies showing a maximum at $1.08 \mathrm{eV}$. Deconvolution of this band shows three components at $1.17 \mathrm{eV}, 1.05 \mathrm{eV}$, and $0.95 \mathrm{eV}$, respectively.

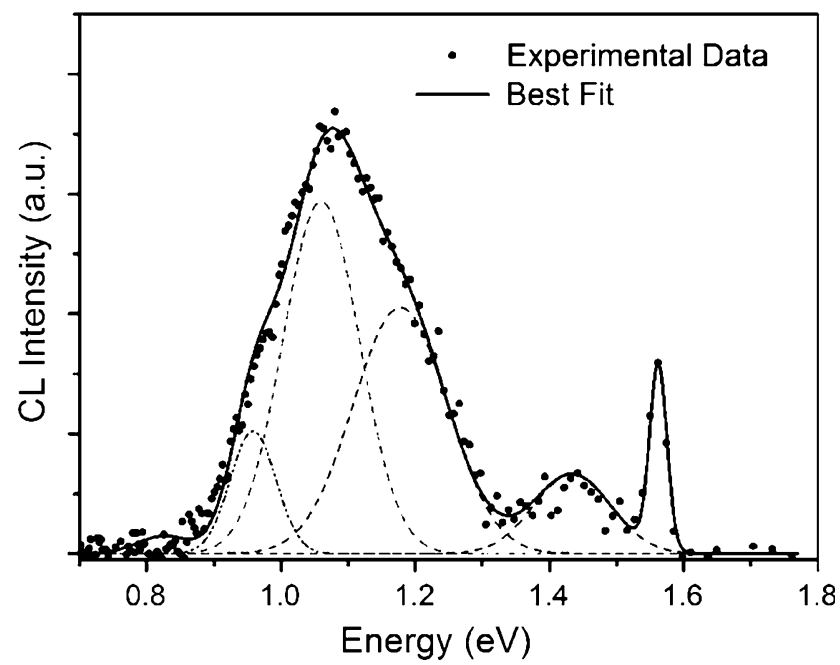

Fig. 5 CL spectrum of sample 3, codoped with Bi and Yb. Gaussian deconvolution of the band centered at $1.1 \mathrm{eV}$ shows this band is formed by three emission peaks. (Full circles) Experimental data, (solid line) Best Fit, and (dash line) Gaussian components

\section{Conclusions}

Bi doped CdTe crystals with two Bi concentrations as well as crystals codoped with $\mathrm{Bi}$ and $\mathrm{Yb}$ have been grown by Bridgman technique. CL measurements show that in the sample with higher $\mathrm{Bi}$ content $\left(7 \times 10^{17}\right.$ at.cm $\left.{ }^{-3}\right)$ a dense network of highly decorated grain boundaries is formed. In the codoped samples, dopant striations are observed which are probably due to the presence of $\mathrm{Yb}$. Bi doping contributes to the appearance of the A luminescence band. Yb causes a blue shift of the deep level band centered at about $1.1 \mathrm{eV}$.

Acknowledgements This work was supported by Projects CAM (S-0505/MAT/0279) and MEC (project MAT 2006/1259).

\section{References}

1. Saucedo E, Fornaro L, Sochinskii NV, Cuña A, Corregidos V, Granados D, Diéguez E (2004) IEEE Trans Nucl Sci 51(6):3105

2. Neretina S, Sochinskii NV, Mascher P, Saucedo E (2005) Mater Res Soc Symp Proc 864:E4.18.1

3. Saucedo E, Herrero CM, Fornaro L, Sochinskii NV, Diéguez E (2005) J Cryst Growth 275(1-2):471

4. Saucedo E, Martínez O, Ruiz CM, Vigil-Galán O, Benito I, Fornaro L, Sochinskii NV, Diéguez E (2006) J Cryst Growth 291(2):416

5. Neretina S, Botton GA, Preston JS, Mascher P (2006) Appl Phys Lett 89:133101

6. Neretina S, Hughes RA, Britten JF, Sochinskii NV, Preston JS, Mascher P (2007) Nanotechnology 18:275301

7. Saucedo E, Ruiz CM, Bermúdez V, Diéguez E, Gombia E, Zappettini A, Baraldi A, Sochinskii NV (2006) J Appl Phys 100(10): 104901 
8. Pal U, Fernández P, Piqueras J, Sochinskii NV, Diéguez E (1995) J Appl Phys 78(3):1992

9. Fernández P, Piqueras J, Sochinskii NV, Muñoz V, Bernardi S (1997) Appl Phys Lett 71(21):3096

10. Franc J, Horodysky P, Grill R, Kubat J, Saucedo E, Sochinskii NV (2006) J Cryst Growth 286:384

11. Castaldini A, Cavallini A, Fraboni B, Fernández P, Piqueras J (1998) J Appl Phys 83:2121

12. Sobiesierski Z, Dharmadasa IM, Williams RH (1988) Appl Phys Lett 53:2623
13. Davis CB, Allred DD, Reyes-Mena A, González-Hernández J, González O, Hess BC, Allred WP (1993) Phys Rev B 47:13369

14. Castaldini A, Cavallini A, Fraboni B, Polenta L, Fernández P, Piqueras J (1996) Phys Rev B 54:7622

15. Stadler W, Hofmann DM, Alt HC, Muschik T, Meyer BK, Weigel E, Müller-Vogt G, Salk M, Rupp E, Benz WK (1995) Phys Rev B 51:10619

16. Shaw DA, Thornton RP (1968) J Mat Sci 3:507

17. Ono H, Kamejima T, Watanabe H, Matsui J (1986) Jpn J Appl Phys 25:L130 